\title{
A systematic review of blockchain
}

\author{
Min Xu ${ }^{*}$, Xingtong Chen and Gang Kou
}

\author{
* Correspondence: xumin@swufe. \\ edu.cn \\ Southwestern University of Finance \\ and Economics, Chengdu, China
}

\begin{abstract}
Blockchain is considered by many to be a disruptive core technology. Although many researchers have realized the importance of blockchain, the research of blockchain is still in its infancy. Consequently, this study reviews the current academic research on blockchain, especially in the subject area of business and economics. Based on a systematic review of the literature retrieved from the Web of Science service, we explore the top-cited articles, most productive countries, and most common keywords. Additionally, we conduct a clustering analysis and identify the following five research themes: "economic benefit," "blockchain technology," "initial coin offerings," "fintech revolution," and "sharing economy." Recommendations on future research directions and practical applications are also provided in this paper.
\end{abstract}

Keywords: Blockchain, Systematic literature review, Business and economics, CiteSpace

\section{Introduction}

The concepts of bitcoin and blockchain were first proposed in 2008 by someone using the pseudonym Satoshi Nakamoto, who described how cryptology and an open distributed ledger can be combined into a digital currency application (Nakamoto 2008). At first, the extremely high volatility of bitcoin and the attitudes of many countries toward its complexity restrained its development somewhat, but the advantages of blockchain-which is bitcoin's underlying technology-attracted increasing attention. Some of the advantages of blockchain include its distributed ledger, decentralization, information transparency, tamper-proof construction, and openness. The evolution of blockchain has been a progressive process. Blockchain is currently delimited to Blockchain 1.0, 2.0, and 3.0, based on their applications. We provide more details on the three generations of blockchain in the Appendix. The application of blockchain technology has extended from digital currency and into finance, and it has even gradually extended into health care, supply chain management, market monitoring, smart energy, and copyright protection (Engelhardt 2017; Hyvarinen et al. 2017; Kim and Laskowski 2018; O'Dair and Beaven 2017; Radanovic and Likic 2018; Savelyev 2018).

Blockchain technology has been studied by a wide variety of academic disciplines. For example, some researchers have studied the underlying technology of blockchain, such as distributed storage, peer-to-peer networking, cryptography, smart contracts, and consensus algorithms (Christidis and Devetsikiotis 2016; Cruz et al. 2018; Kraft 2016). Meanwhile, legal researchers are interested in the regulations and laws

(c) The Author(s). 2019 Open Access This article is distributed under the terms of the Creative Commons Attribution 4.0 International License (http://creativecommons.org/licenses/by/4.0/), which permits unrestricted use, distribution, and reproduction in any medium, provided you give appropriate credit to the original author(s) and the source, provide a link to the Creative Commons license, and indicate if changes were made. 
governing blockchain-related technology (Kiviat 2015; Paech 2017). As the old saying goes: scholars in different disciplines have many different analytical perspectives and "speak many different languages." This paper focuses on analyzing and combing papers in the field of business and economics. We aim to identify the key nodes (e.g., the most influential articles and journals) in the related research and to find the main research themes of blockchain in our discipline. In addition, we hope to offer some recommendations for future research and provide some suggestions for businesses that wish to apply blockchain in practice.

This study will conduct a systematic and objective review that is based on data statistics and analysis. We first describe the overall number and discipline distribution of blockchain-related papers. A total of 756 journal articles were retrieved. Subsequently, we refined the subject area to business and economics, and were able to add 119 articles to our further analysis. We then explored the influential countries, journals, articles, and most common keywords. On the basis of a scientific literature analysis tool, we were able to identify five research themes on blockchain. We believe that this data-driven literature review will be able to more objectively present the status of this research.

The rest of this paper is organized as follows. In the next section, we provided an overview of the existing articles in all of the disciplines. We holistically describe the number of papers related to blockchain and discipline distribution of the literature. We then conduct a further analysis in the subject field of business and economics, where we analyze the countries, publications, highly cited papers, and so on. We also point out the main research themes of this paper, based on CiteSpace. This is followed by recommendations for promising research directions and practical applications. In the last section, we discuss the conclusions and limitations.

\section{Overview of the current research}

In our research, we first conducted a search on Web of Science Core Collection (WOS), including four online databases: Science Citation Index Expanded (SCI-EXPANDED), Social Sciences Citation Index (SSCI), Arts \& Humanities Citation Index (A\&HCI), and Emerging Sources Citation Index (ESCI). We chose WOS because the papers in these databases can typically reflect scholarly attention towards blockchain. When searching the term "blockchain" as a topic, we found a total of 925 records in these databases. After filtering out the less representative record types, we reduced these papers to 756 articles that were then used for further analysis. We extracted the full bibliographic record of the articles that we identified from WOS, including information on the title, author, keywords, abstract, journal, year, and other publication information. These records were then exported to CiteSpace for subsequent analysis. CiteSpace is a scientific literature analysis tool that enables us to visualize trends and patterns in the scientific literature (Chen 2004). In this paper, CiteSpace is used to visually represent complex structures for statistical analysis and to conduct cluster analysis.

Table 1 shows the number of academic papers published per year. We have listed the number of all of the publications in WOS, the number of articles in all of the disciplines, and the number of articles in business and economics subjects. It should be noted that we retrieved the literature on March 25, 2019. Therefore, the number of articles in 2019 is relatively small. The number of papers has continued to grow in recent years, which suggests that there is a growing interest in blockchain. All of the extracted 
Table 1 Number of academic papers on blockchain

\begin{tabular}{llll}
\hline & WOS-All & $\begin{array}{l}\text { WOS- } \\
\text { Articles }\end{array}$ & $\begin{array}{l}\text { WOS- } \\
\text { Business \& Economics }\end{array}$ \\
\hline Before2015 & 0 & 0 & 0 \\
2015 & 4 & 1 & 0 \\
2016 & 40 & 28 & 5 \\
2017 & 200 & 158 & 45 \\
2018 & 553 & 453 & 61 \\
\#2019 & 138 & 116 & 8 \\
Total & 925 & 756 & 119 \\
\hline
\end{tabular}

papers in WOS were published after 2015, which is seven years after blockchain and bitcoin was first described by Nakamoto. In these initial seven years, many papers were published online or indexed by other databases. However, we have not discussed these papers here. We only chose WOS, representative high-level literature databases. This is the most common way of doing a literature review (Ipek 2019).

In the 756 articles that we managed to retrieve, the three most common keywords besides blockchain are bitcoin, smart contract, and cryptocurrency, with the frequency of 113 times, 72 times, and 61 times, respectively. This shows that the majority of the literature mentions the core technology of blockchain and its most widely known application-bitcoin.

In WOS, each article is assigned to one or more subject categories. Therefore, we use CiteSpace to visualize what research areas are involved in current research on blockchain. Figure 1 shows a network of such subject categories. The most common category is Computer Science, which has the largest circle, followed by Engineering and Telecommunications. Business and Economics is also a common

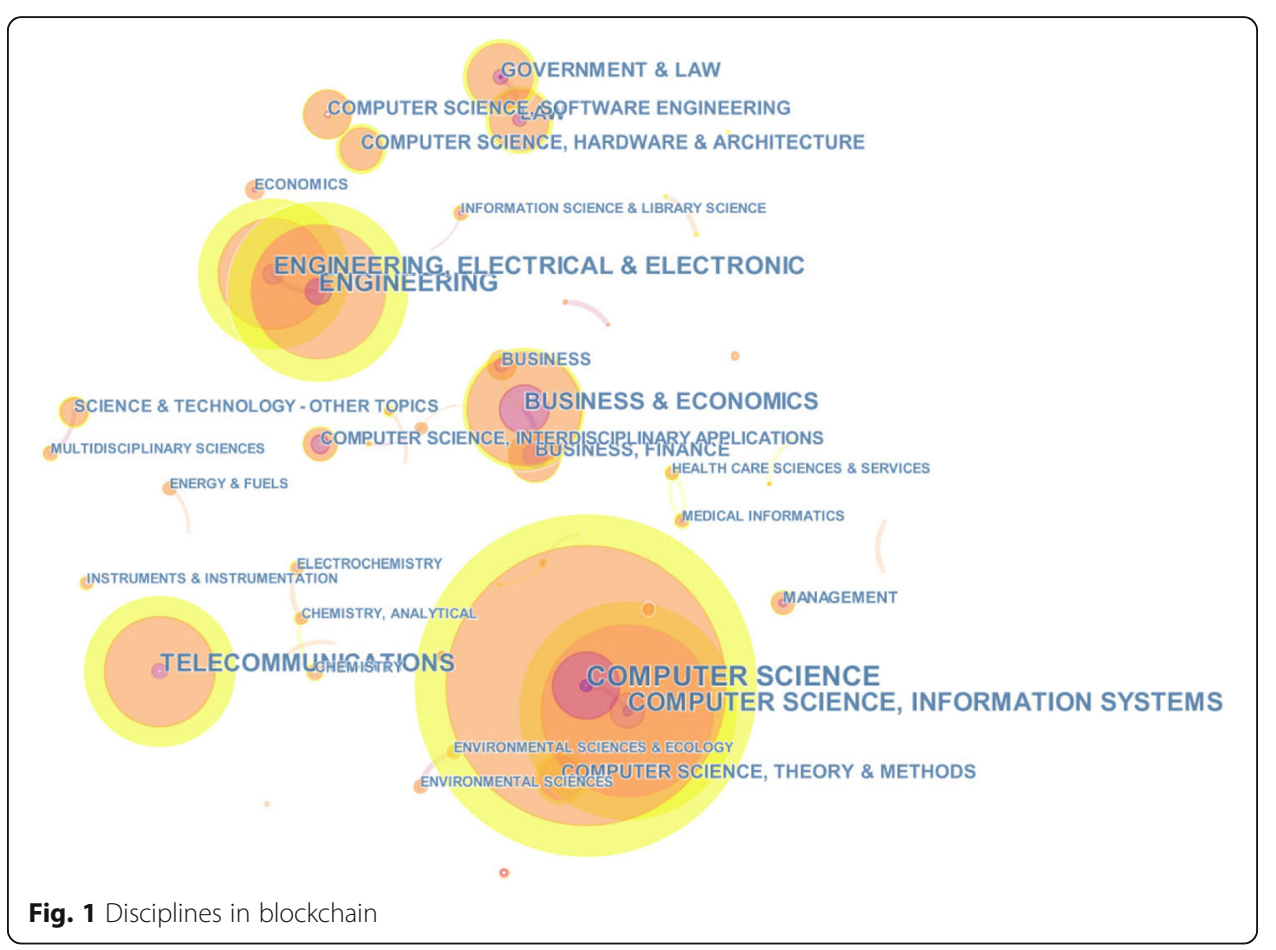


subject area for blockchain. Consequently, in the following session, we will conduct further analysis in this field.

\section{Articles in business and economics}

Given that the main objective of our research was to understand the research of blockchain in the area of economics and management, we conduct an in-depth analysis on the papers in this field. We refined the research area to Business and Economics, and we finally retrieved 119 articles from WOS. In this session, we analyzed their published journals, research topics, citations, and so on, to depict the research status of blockchain in the field of business and economics more comprehensively.

There are several review papers on blockchain. Each of these paper contains a summary of multiple research topics, instead of a single topic. We do not include these literature reviews in our paper. However, it is undeniable that these articles also play an important role on the study of blockchain. For instance, Wang et al. (2019) investigate the influence of blockchain on supply chain practices and policies. Zhao et al. (2016) suggest blockchain will widely adopted in finance and lead to many business innovations and research opportunities.

\section{Countries}

The United States, the United Kingdom, and Germany are the top three countries by the number of papers published on blockchain; the specific data are shown in Table 2. The United States released more papers than the other countries and it produced more than one-third of the total articles. As of the time of data collection, China contributed 11 papers, ranking fourth. The 119 papers in total are drawn from 17 countries and regions. In contrast, we searched "big data" and "financial technology" in the same way, and found 286 papers on big data that came from 24 countries, while 779 papers on fintech came from 43 countries. This shows that blockchain is still an emerging research field, and it needs more countries and scholars to join in the research effort.

\section{Journals}

We counted the journals published in these papers and we found that 44 journals published related papers. Table 3 lists the top 11 journals to have published blockchain research. First is "Strategic Change: Briefings in Entrepreneurial Finance," followed by "Financial Innovation" and "Asia Pacific Journal of Innovation and Entrepreneurship." The majority of papers in the journal "Strategic Change" were published in 2017, except for one in 2018 and one in 2019. Papers in the journal "Financial Innovation" were

Table 2 Main research countries

\begin{tabular}{lll}
\hline Country & No. of Papers & $\% / 119$ \\
\hline USA & 41 & $34.454 \%$ \\
ENGLAND & 14 & $11.765 \%$ \\
GERMANY & 12 & $10.084 \%$ \\
PEOPLES R CHINA & 11 & $9.244 \%$ \\
CANADA & 8 & $6.723 \%$ \\
FRANCE & 8 & $6.723 \%$ \\
\hline
\end{tabular}


Table 3 Top 11 journals publishing blockchain research

\begin{tabular}{ll}
\hline Source Title & No. of Papers \\
\hline Strategic Change- Briefings in Entrepreneurial Finance & 12 \\
Financial Innovation & 6 \\
Asia Pacific Journal of Innovation and Entrepreneurship & 5 \\
Journal of Risk and Financial Management & 4 \\
Mit Sloan Management Review & 4 \\
Quality- Access to Success & 4 \\
Technological Forecasting and Social Change & 4 \\
Technology Innovation Management Review & 4 \\
Business Horizons & 3 \\
Intelligent Systems in Accounting Finance \& Management & 3 \\
Journal of Risk Finance & 3
\end{tabular}

generally published in 2016, with one published in 2017 and one in 2019. All five of the papers in the journal "Asia Pacific Journal of Innovation and Entrepreneurship" were published in 2017.

\section{Cited references}

Table 4 presents the top six cited publications, which were cited no less than five times. The list consists of three books and three journal articles. Some of these publications introduce blockchain from a technical perspective and some from an application perspective. Swan's (2015) book illustrates the application scenarios of blockchain technology. In this book, the author describes that blockchain is essentially a public ledger with potential as a decentralized digital repository of all assets-not only tangible assets but also intangible assets such as votes, software, health data, and ideas. Tapscott and Tapscott's (2016) book explains why blockchain technology will fundamentally change the world. Yermack (2017) points out that blockchain will have a huge impact and will present many challenges to corporate governance. Böhme et al. (2015) introduce bitcoin, the first and most famous application of blockchain. Narayanan et al. (2016) also focus on bitcoin and explain how bitcoin works at a technical level. Lansiti and Lakhani (2017) argue it will take years to truly transform the blockchain because it is a fundamental rather than destructive technology, which will not drive implementation, and companies will need other incentives to adopt blockchain.

Table 4 Cited references

\begin{tabular}{|c|c|c|c|}
\hline Title & Author \& Year & Type & Citations \\
\hline Blockchain: Blueprint for a New Economy & (Swan 2015) & book & 21 \\
\hline $\begin{array}{l}\text { Blockchain revolution: how the technology behind bitcoin is changing } \\
\text { money, business, and the world }\end{array}$ & $\begin{array}{l}\text { (Tapscott and } \\
\text { Tapscott 2016) }\end{array}$ & book & 17 \\
\hline Bitcoin: Economics, Technology, and Governance & (Böhme et al. 2015) & article & 7 \\
\hline Corporate Governance and Blockchains & (Yermack 2017) & article & 5 \\
\hline $\begin{array}{l}\text { Bitcoin and Cryptocurrency Technologies: A Comprehensive } \\
\text { Introduction }\end{array}$ & $\begin{array}{l}\text { (Narayanan et al. } \\
\text { 2016) }\end{array}$ & book & 5 \\
\hline The Truth about Blockchain & $\begin{array}{l}\text { (Lansiti and Lakhani } \\
\text { 2017) }\end{array}$ & article & 5 \\
\hline
\end{tabular}




\section{Most influential articles}

These 119 papers were cited 314 times in total, and 270 times without selfcitations. The number of articles that they cited are 221, of which 197 are nonself-citations. The most influential articles with more than 10 citations are listed in Table 5. The most popular article in our dataset is Lansiti and Lakhani (2017), with 49 citations in WOS. This suggests that this article has had a strong influence on the research of blockchain. This paper believes there is still a distance to the real application of the blockchain. The other articles describe how blockchain affects and works in various areas, such as financial services, organizational management, and health care. Since blockchain is an emerging technology, it is particularly necessary to explore how to combine blockchains with various industries and fields.

By comparing the journals in Tables 4 and 5, we find that some journals appeared in both of the lists, such as Financial Innovation. In other words, papers on blockchain are more welcomed in these journals and the journal's papers are highly recognized by other scholars. Meanwhile, although journals such as Harvard Business Review have only published a few papers related to blockchain, they are highly cited. Consequently, the journals in both of these lists are of great importance.

\section{Research themes}

Addressing research themes is crucial to understanding a research field and exploring future research directions. This paper explored the research topic based on keywords. Keywords are representative and concise descriptions of article content. First, we analyzed the most common keywords used by the papers. We find that the top five most frequently used keywords are "blockchain," "bitcoin," "cryptocurrency," "fintech," and "smart contract." Although the potential for blockchain applications goes way beyond digital currencies, bitcoin and other cryptocurrencies-as an important blockchain application scenario in the finance industry-were widely discussed in these articles. Smart contracts allow firms to set up automated transactions in blockchains, thus

Table 5 Most cited articles

\begin{tabular}{|c|c|c|c|}
\hline Title & Author \& Year & Journal & $\begin{array}{l}\text { Citations } \\
\text { in WOS }\end{array}$ \\
\hline The Truth about Blockchain & $\begin{array}{l}\text { (Lansiti and } \\
\text { Lakhani 2017) }\end{array}$ & Harvard Business Review & 49 \\
\hline $\begin{array}{l}\text { Blockchain-based sharing services: What blockchain } \\
\text { technology can contribute to smart cities }\end{array}$ & $\begin{array}{l}\text { (Sun et al. } \\
\text { 2016) }\end{array}$ & Financial Innovation & 19 \\
\hline Citizen utilities: The emerging power paradigm & $\begin{array}{l}\text { (Green and } \\
\text { Newman 2017) }\end{array}$ & Energy Policy & 18 \\
\hline Blockchain and Its Coming Impact on Financial Services & $\begin{array}{l}\text { (Fanning and } \\
\text { Centers 2016) }\end{array}$ & $\begin{array}{l}\text { Journal of Corporate } \\
\text { Accounting and Finance }\end{array}$ & 15 \\
\hline Toward Blockchain-Based Accounting and Assurance & $\begin{array}{l}\text { (Dai and } \\
\text { Vasarhelyi 2017) }\end{array}$ & $\begin{array}{l}\text { Journal of Information } \\
\text { Systems }\end{array}$ & 12 \\
\hline How Blockchain Will Change Organizations & $\begin{array}{l}\text { (Tapscott and } \\
\text { Tapscott 2017) }\end{array}$ & $\begin{array}{l}\text { Mit Sloan Management } \\
\text { Review }\end{array}$ & 11 \\
\hline $\begin{array}{l}\text { Hitching Healthcare to the Chain: An Introduction to } \\
\text { Blockchain Technology in the Healthcare Sector }\end{array}$ & $\begin{array}{l}\text { (Engelhardt } \\
\text { 2017) }\end{array}$ & $\begin{array}{l}\text { Technology Innovation } \\
\text { Management Review }\end{array}$ & 10 \\
\hline
\end{tabular}

a Data last updated on 2019-04-08 
playing a fundamentally supporting role in blockchain applications. Similar to the literature in all of the subject areas, studies in business and economics also frequently use bitcoin, cryptocurrency, and smart contract as their keywords. The difference is that many researchers have combined blockchain with finance, regarding it as an important financial technology.

After analyzing the frequency of keywords, we conducted a keywords clustering analysis to identify the research themes. As shown in Fig. 2, five clusters were identified through the log-likelihood ratio (LLR) algorithm in Citespace, they are: cluster \#0 "economic benefit," cluster \#1 "blockchain technology," cluster \#2 "initial coin offerings," cluster \#3 "fintech revolution," and cluster \#4 "sharing economy."

Many researchers have studied the economic benefits of blockchain. They suggest the application of blockchain technology to streamline transactions and settlement processes can effectively reduce the costs associated with manual operations. For instance, in the health care sector, blockchain can play an important role in centralizing research data, avoiding prescription drug fraud, and reducing administrative overheads (Engelhardt 2017). In the music industry, blockchain could improve the accuracy and availability of copyright data and significantly improve the transparency of the value chain (O'Dair and Beaven 2017). Swan (2017) expound the economic value of block chain through four typical applications, such as digital asset registries, leapfrog technology, long-tail personalized economic services, and payment channels and peer banking services.

The representative paper for cluster "blockchain technology" was published by Lansiti and Lakhani (2017), who analyze the inherent features of blockchain and pointed out that we still have a lot to do to apply blockchain extensively. Other researchers have explored the characteristics of blockchain technology from multiple perspectives. For example, Xu (2016) explores the types of fraud and malicious activities that blockchain technology can prevent and identifies attacks to which

\section{\#4 sharing economy \#1 blockchain technology}

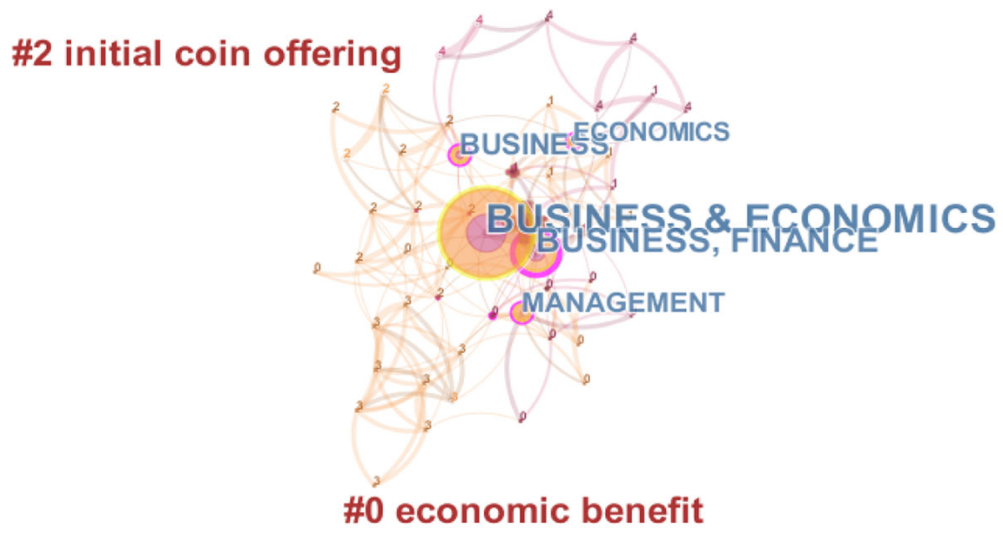

\#3 fintech revolution

Fig. 2 Disciplines and topics 
blockchain remains vulnerable. Meanwhile, Aune et al. (2017) propose a cryptographic approach to solve information leakage problems on a blockchain.

Initial coin offering (ICO) is also a research topic of great concern to scholars. Many researchers analyze the determinants of the success of initial coin offerings (Adhami et al. 2018; Ante et al. 2018). For example, Fisch (2019) assesses the determinants of the amount raised in ICOs and discusses the role of signaling ventures' technological capabilities in ICOs. Deng et al. (2018) argue the outright ban on ICOs might hamper revolutionary technological development and they provided some regulatory reform suggestions on the current ICO ban in China.

Many researchers have explored blockchain's support for various industries. The fintech revolution brought by the blockchain has received extensive attention (Yang and Li 2018). Researchers agree that this nascent technology may transform traditional trading methods and practice in financial industry (Ashta and Biot-Paquerot 2018; Chen et al. 2017; Kim and Sarin 2018). For instance, Gomber et al. (2018) discuss transformations in four areas of financial services: operations management, payments, lending, and deposit services. Dierksmeier and Seele (2018) address the impact of blockchain technology on the nature of financial transactions from a business ethics perspective.

Another cluster corresponds to the sharing economy. A handful of researchers have focused on this field and they have discussed the supporting role played by blockchain in the sharing economy. Pazaitis et al. (2017) describe a conceptual economic model of blockchain-based decentralized cooperation that might better support the dynamics of social sharing. Sun et al. (2016) discuss the contribution of emerging blockchain technologies to the three major factors of the sharing economy (i.e., human, technology, and organization). They also analyze how blockchain-based sharing services contribute to smart cities.

\section{Discussion}

In this section, we will discuss the following issues: (1) What will be the future research directions for blockchain? (2) How can businesses benefit from blockchain? We hope that our discussions will be able to provide guidance for future academic development and social practice.

\section{(1) What will be the future research directions for blockchain?}

In view of the five themes mentioned in this paper, we provide some recommendations for future research in this section.

The economic benefits of blockchain have been extensively studied in previous research. For individual businesses, it is important to understand the effects of blockchain applications on the organizational structure, mode of operation, and management model of the business. For the market as a whole, it is important to determine whether blockchain can resolve the market failures that are brought about by information asymmetry, and whether it can increase market efficiency and social welfare. However, understanding the mechanisms through which blockchain influences corporate and market efficiency will require further academic inquiry. 
For researchers of blockchain technology, this paper suggests that we should pay more attention to privacy protection and security issues. Despite the fact that all of the blockchain transactions are anonymous and encrypted, there is still a risk of the data being hacked. In the security sector, there is a view that absolute security can never be guaranteed wherever physical contact exists. Consequently, the question of how to share transaction data while also protecting personal data privacy are particularly vital issues for both academic and social practice.

Initial coin offering and cryptocurrency markets have grown rapidly. They bring many interesting questions, such as how to manage digital currencies. Although the majority of the previous research has focused on the determinants of success of initial coin offerings, we believe that future research will discuss how to regulate cryptocurrency and the ICO market. The success of blockchain technology in digital currency applications prior to 2015 caught the attention of many traditional financial institutions. As blockchain has continued to reinvent itself, in 2019 it is now more than capable of meeting the needs of the finance industry. We believe that blockchain is able to achieve large-scale applications in many areas of finance, such as banking, capital markets, Internet finance, and related fields. The deep integration of blockchain technology and fintech will continue to be a promising research direction.

The sharing economy is often defined as a peer-to-peer based activity of sharing goods and services among individuals. In the future, sharing among enterprises may become an important part of the new sharing economy. Consequently, building the interconnection of blockchains may become a distinct trend. These interconnections will facilitate the linkages between processes of identity authentication, supply chain management, and payments in commercial operations. They will also allow for instantaneous information exchange and data coordination among enterprises and industries.

\section{(2) How can businesses benefit from blockchain?}

Businesses can leverage blockchains in a variety of ways to gain an advantage over their competitors. They can streamline their core business, reduce transaction costs, and make intellectual property ownership and payments more transparent and automated (Felin and Lakhani 2018). Many researchers have discussed the application of blockchain in business. After analyzing these studies, we believe that enterprises can consider applying blockchain technology in the four aspects that follow.

\section{(a) Accounting settlement and crowdfunding}

Bitcoin or another virtual currency supported by blockchain technology can help businesses to solve funding-related problems. For instance, cryptocurrencies support companies who wish to implement non-cash payments and accounting settlement. The automation of electronic transaction management accounting improves the level of control of monetary business execution, both internally and externally (Zadorozhnyi et al. 2018). In addition, blockchain technology represents an emerging source of venture capital crowdfunding (O'Dair and Owen 2019). Investors or 
founders of enterprises can obtain alternative entrepreneurial finance through token sales or initial coin offerings. Companies can handle financial-related issues more flexibly by holding, transferring, and issuing digital currencies that are based on blockchain technology.

(b) Data storage and sharing

As the most valuable resource, data plays a vital role in every enterprise. Blockchain provide a reliable storage and efficient use of data (Novikov et al. 2018). As a decentralized and secure ledger, blockchain can be used to manage digital asset for many kinds of companies (Dutra et al. 2018). Decentralized data storage means you do not give the data to a centralized agency but give it instead to people around the world because no one can tamper with the data on the blockchain. Businesses can use blockchain to store data, improve the transparency and security of the data, and prevent the data from being tampered with. At the same time, blockchain also supports data sharing. For instance, all of the key parties in the accounting profession leverage an accountancy blockchain to aggregate and share instances of practitioner misconduct across the country on a nearly real-time basis (Sheldon 2018).

(c) Supply chain management

Blockchain technology has the potential to significantly change supply chain management (SCM) (Treiblmaier 2018). Recent adoptions of the Internet of Things and blockchain technologies support better supply-chain provenance (Kim and Laskowski 2018). When the product goes from the manufacturer to the customer, important data are recorded in the blockchain. Companies can trace products and raw materials to effectively monitor product quality.

\section{(d) Smart trading}

Businesses can build smart contracts on blockchain, which is widely used to implement business collaborations in general and inter-organizational business processes in particular. Enterprises can automate transactions based on smart contracts on block chains without manual confirmation. For instance, businesses can file taxes automatically under smart contracts (Vishnevsky and Chekina 2018).

\section{Conclusions}

This paper reviews 756 articles related to blockchain on the Web of Science Core Collection. It shows that the most common subject area is Computer Science, followed by Engineering, Telecommunications, and Business and Economics. In the research of Business and Economics, several key nodes are identified in the literature, such as the top-cited articles, most productive countries, and most common keywords. After a cluster analysis of the keywords, we identified the five most popular research themes: "economic benefit," "blockchain technology," "initial coin offerings," "fintech revolution," and "sharing economy." 
As an important emerging technology, blockchain will play a role in many fields. Therefore, we believe that the issues related to commercial applications of blockchain are critical for both academic and social practice. We propose several promising research directions. The first important research direction is understanding the mechanisms through which blockchain influences corporate and market efficiency. The second potential research direction is privacy protection and security issues. The third relates to how to manage digital currencies and how to regulate the cryptocurrency market. The fourth potential research direction is how to deeply integrate blockchain technology and fintech. The final topic is cross-chain technology-if each industry has its own blockchain system, then researchers and developers must discover new ways to exchange data. This is the key to achieving the Internet of Value. Thus, cross-chain technology will become an increasingly important topic as time goes on.

Businesses can benefit considerably from blockchain technology. Therefore, we suggest that the application of blockchain be taken into consideration when businesses have the following requirements: accounting settlement and crowdfunding, data storage and sharing, supply chain management, and smart trading.

Our study has recognized some limitations. First, this paper only analyzes the literature in Web of Science Core Collection databases (WOS), which may lead to the incompleteness of the relevant literature. Second, we filter our literature base on the subject category in WOS. In this process, we may have omitted some relevant research. Third, our recommendations have subjective limitations. We hope to initiate more research and discussions to address these points in the future.

\section{Appendix}

\section{Three generations of blockchain}

The scope of blockchain applications has increased from virtual currencies to financial applications to the entire social realm. Based on its applications, blockchain is delimited to Blockchain 1.0, 2.0, and 3.0.

\section{Blockchain 1.0}

Blockchain 1.0 was related to virtual currencies, such as bitcoin, which was not only the first and most widely used digital currency but it was also the first application of blockchain technology (Mainelli and Smith 2015). Digital currencies can reduce many of the costs associated with traditional physical currencies, such as the costs of circulation. Blockchain 1.0 produced a great many applications, one of which was Bitcoin. Most of these applications were digital currencies and tended to be used commercially for small-value payments, foreign exchange, gambling, and money laundering. At this stage, blockchain technology was generally used as a cryptocurrency and for payment systems that relied on cryptocurrency ecosystems.

\section{Blockchain 2.0}

Broadly speaking, Blockchain 2.0 includes Bitcoin 2.0, smart-contracts, smart-property, decentralized applications (Dapps), decentralized autonomous organizations (DAOs), and decentralized autonomous corporations (DACs) (Swan 2015). However, most people understand Blockchain 2.0 as applications in other areas of finance, where it is 
mainly used in securities trading, supply chain finance, banking instruments, payment clearing, anti-counterfeiting, establishing credit systems, and mutual insurance. The financial sector requires high levels of security and data integrity, and thus blockchain applications have some inherent advantages. The greatest contribution of Blockchain 2.0 was the idea of using smart-contracts to disrupt traditional currency and payment systems. Recently, the integration of blockchain and smart contract technology has become a popular research topic in problem resolution. For example, Ethereum, Codius, and Hyperledger have established programmable contract language and executable infrastructure to implement smart contracts.

\section{Blockchain 3.0}

In 'Blockchain: Blueprint for a New Economy', Blockchain 3.0 is described as the application of blockchain in areas other than currency and finance, such as in government, health, science, culture, and the arts (Swan 2015). Blockchain 3.0 aims to popularize the technology, and it focuses on the regulation and governance of its decentralization in society. The scope of this type of blockchain and its potential applications suggests that blockchain technology is a moving target (Crosby et al. 2016). Blockchain 3.0 envisions a more advanced form of "smart contracts" to establish a distributed organizational unit that makes and is subject to its own laws and which operates with a high degree of autonomy (Pieroni et al. 2018).

The integration of blockchain with tokens is an important combination of Blockchain 3.0. Tokens are proofs of digital rights, and blockchain tokens are widely recognized thanks to Ethereum and its ERC20 standard. Based on this standard, anyone can issue a custom token on Ethereum and this token can represent any right or value. Tokens refer to economic activities generated through the creation of encrypted tokens, which are principally but not exclusively based on the ERC20 standard. Tokens can serve as a form of validation of any right, including personal identity, academic diplomas, currency, receipts, keys, event tickets, rebate points, coupons, stocks, and bonds. Consequently, tokens can validate virtually any right that exists within a society. Blockchain is the back-end technology of the new era, while tokens are its front-end economic face. The combination of the two will bring about major societal transformation. Meanwhile, Blockchain 3.0 and its token economy continue to evolve.

Abbreviations

ICO: Initial coin offering; WOS: Web of Science Core Collection

Acknowledgements

Not applicable.

Authors' contributions

The first author contributed by retrieving literature and conducting data analysis. The second and third author contributed by writing the paper, especially the Discussion and Appendix. All authors read and approved the final manuscript.

\section{Funding}

This research is supported by grants from National Natural Science Foundation of China (Nos. 71701168 and 71701034).

Availability of data and materials

Data used in this paper were collected from Web of Science Core Collection. 
Received: 1 May 2019 Accepted: 24 June 2019

Published online: 04 July 2019

\section{References}

Adhami S, Giudici G, Martinazzi S (2018) Why do businesses go crypto? An empirical analysis of initial coin offerings. J Econ Bus 100:64-75

Ante L, Sandner P, Fiedler I (2018) Blockchain-based ICOs: pure hype or the Dawn of a new era of startup financing? J Risk Financ Manage 11(4):80

Ashta A, Biot-Paquerot G (2018) FinTech evolution: strategic value management issues in a fast changing industry. Strategic Change-Briefings in Entrepreneurial Finance 27(4):301-311

Aune RT, Krellenstein A, O'Hara M, Slama O (2017) Footprints on a Blockchain: trading and information leakage in distributed ledgers. J Trading 12(3):5-13

Böhme R, Christin N, Edelman B, Moore T (2015) Bitcoin: economics, technology, and governance. J Econ Perspect 29(2):213-238

Chen C (2004) Searching for intellectual turning points: progressive knowledge domain visualization. Proc Natl Acad Sci U S A 101 (suppl:5303-5310

Chen Z, Li Y, Wu Y, Luo J (2017) The transition from traditional banking to mobile internet finance: an organizational innovation perspective - a comparative study of Citibank and ICBC. Financial Innovation 3(1):12

Christidis K, Devetsikiotis M (2016) Blockchains and smart contracts for the internet of things. leee Access 4:2292-2303

Crosby M, Pattanayak P, Verma S (2016) Blockchain technology: beyond bitcoin. Appl Innov 2:6-19

Cruz JP, Kaji Y, Yanai N (2018) RBAC-SC: role-based access control using smart contract. leee Access 6:12240-12251

Dai J, Vasarhelyi MA (2017) Toward Blockchain-based accounting and assurance. J Inf Syst 31(3):5-21

Deng H, Huang RH, Wu Q (2018) The regulation of initial coin offerings in China: problems, prognoses and prospects. Eur Bus Organ Law Rev 19(3):465-502

Dierksmeier C, Seele P (2018) Cryptocurrencies and business ethics. J Bus Ethics 152(1):1-14

Dutra A, Tumasjan A, Welpe IM (2018) Blockchain is changing how media and entertainment companies compete. MIT Sloan Manag Rev 60(1):39-3+

Engelhardt MA (2017) Hitching healthcare to the chain: an introduction to Blockchain Technology in the Healthcare Sector. Technol Innov Manage Rev 7(10):22-34

Fanning K, Centers DP (2016) Blockchain and its coming impact on financial services. J Corp Account Finance 27(5):53-57

Felin T, Lakhani K (2018) What problems will you solve with Blockchain? MIT Sloan Manag Rev 60(1):32-3+

Fisch C (2019) Initial coin offerings (ICOs) to finance new ventures. J Bus Ventur 34(1):1-22

Gomber P, Kauffman RJ, Parker C, Weber BW (2018) On the Fintech revolution: interpreting the forces of innovation, disruption, and transformation in financial services. J Manag Inf Syst 35(1):220-265

Green J, Newman P (2017) Citizen utilities: the emerging power paradigm. Energy Policy 105:283-293

Hyvarinen H, Risius M, Friis G (2017) A Blockchain-based approach towards overcoming financial fraud in public sector services. Bus Inf Syst Eng 59(6):441-456

Ipek I (2019) Organizational learning in exporting: a bibliometric analysis and critical review of the empirical research. Int Bus Rev 28(3):544-559

Kim HM, Laskowski M (2018) Toward an ontology-driven blockchain design for supply-chain provenance. Intell Syst Account Finance Manage 25(1):18-27

Kim S, Sarin A (2018) Distributed ledger and Blockchain technology: framework and use cases. J Invest Manage 16(3):90-101

Kiviat TI (2015) Beyond bitcoin: issues in regulating blockchain transactions. Duke Law J 65(3):569-608

Kraft D (2016) Difficulty control for blockchain-based consensus systems. Peer-to-Peer Networking and Applications 9(2):397-413

Lansiti M, Lakhani KR (2017) The truth about Blockchain. Harv Bus Rev 95(1):119-127

Mainelli M, Smith M (2015) Sharing ledgers for sharing economies: an exploration of mutual distributed ledgers (aka blockchain technology). J Financial Perspect 3(3):38-58

Nakamoto S (2008) Bitcoin: a peer-to-peer electronic cash system

Narayanan A, Bonneau J, Felten E, Miller A, Goldfeder S (2016). Bitcoin and cryptocurrency technologies: A Comprehensive Introduction. Princeton University Press: 336

Novikov SP, Mikheenko OV, Kulagina NA, Kazakov OD (2018) Digital registry of professional competences of the population drawing on distributed registries and smart contracts technologies. Biznes Informatika Business Inform 46(4):43-53

O'Dair M, Beaven Z (2017) The networked record industry: how blockchain technology could transform the record industry. Strateg Change Brief Entrep Finance 26(5):471-480

O'Dair M, Owen R (2019) Financing new creative enterprise through blockchain technology: opportunities and policy implications. Strateg Change Brief Entrep Finance 28(1):9-17

Paech P (2017) The governance of Blockchain financial networks. Mod Law Rev 80(6):1073-1110

Pazaitis A, De Filippi P, Kostakis V (2017) Blockchain and value systems in the sharing economy: the illustrative case of Backfeed. Technol Forecast Soc Chang 125:105-115

Pieroni A, Scarpato N, Di Nunzio L, Fallucchi F, Raso M (2018) Smarter city: smart energy grid based on blockchain technology. Int J Adv Sci Eng Inf Technol 8(1):298-306

Radanovic I, Likic R (2018) Opportunities for use of Blockchain Technology in Medicine. Appl Health Econ Health Policy 16(5):583-590

Savelyev A (2018) Copyright in the blockchain era: promises and challenges. Comput Law Secur Rev 34(3):550-561

Sheldon MD (2018) Using Blockchain to aggregate and share misconduct issues across the accounting profession. Curr Issues Audit 12(2):A27-A35

Sun J, Yan J, Zhang KZK (2016) Blockchain-based sharing services: what blockchain technology can contribute to smart cities. Financ Innov 2(1):26

Swan M (2015). Blockchain: Blueprint for a New Economy. O'Reilly Media: 152

Swan M (2017) Anticipating the economic benefits of Blockchain. Technol Innov Manage Rev 7(10):6-13 
Tapscott D, Tapscott A (2016) Blockchain revolution: how the technology behind bitcoin is changing money, business, and the world. Portfolio: 368

Tapscott D, Tapscott A (2017) How Blockchain will change organizations. MIT Sloan Manag Rev 58(2):10-13

Treiblmaier H (2018) The impact of the blockchain on the supply chain: a theory-based research framework and a call for action. Supply Chain Manage Int J 23(6):545-559

Vishnevsky VP, Chekina VD (2018) Robot vs. tax inspector or how the fourth industrial revolution will change the tax system: a review of problems and solutions. J Tax Reform 4(1):6-26

Wang YL, Han JH, Beynon-Davies P (2019) Understanding blockchain technology for future supply chains: a systematic literature review and research agenda. Supply Chain Manage Int J 24(1):62-84

Xu JJ (2016) Are blockchains immune to all malicious attacks? Financ Innov 2(1):25

Yang D, Li M (2018) Evolutionary approaches and the construction of technology-driven regulations. Emerg Mark Financ Trade 54(14):3256-3271

Yermack D (2017) Corporate governance and Blockchains. Rev Finance 21(1):7-31

Zadorozhnyi ZMV, Murayskyi W, Shevchuk OA (2018) Management accounting of electronic transactions with the use of cryptocurrencies. Financ Credit Activ Probl Theory Pract 3(26):169-177

Zhao JL, Fan S, Yan J (2016) Overview of business innovations and research opportunities in blockchain and introduction to the special issue. Financ Innov 2(1):28

\section{Publisher's Note}

Springer Nature remains neutral with regard to jurisdictional claims in published maps and institutional affiliations.

Submit your manuscript to a SpringerOpen ${ }^{\circ}$ journal and benefit from:

- Convenient online submission

- Rigorous peer review

- Open access: articles freely available online

High visibility within the field

- Retaining the copyright to your article

Submit your next manuscript at $\boldsymbol{\nabla}$ springeropen.com 